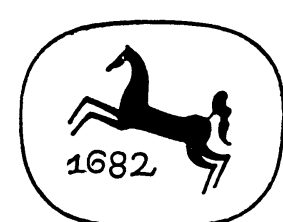

ENGAGIERTER EXPRESSIONISMUS 


\section{Engagierter Expressionismus}

POLITIK UND LITERATUR

ZWISCHEN WELTKRIEG UND WEIMARER

REPUBLIK

EINE ANALYSE EXPRESSIONISTISCHER

ZEITSCHRIFTEN

J. B. METZLERSCHE

VERLAGSBUCHHANDLUNG

STUTTGART 
Die in [ ] stehenden Zahlen verweisen auf die Anmerkungen

ISBN 978-3-476-99732-6 ISBN 978-3-476-99731-9 (eBook) DOI 10.1007/978-3-476-99731-9

(C) Springer-Verlag GmbH Deutschland 1970 Ursprünglich erschienen bei J. B. Metzlersche Verlagsbuchhandlung und Carl Ernst Poeschel Verlag GmbH in Stuttgart 1970 
Die vorliegende Studie versucht, die Stellung des Expressionismus zwischen Kunst und Politik, zwischen Ästhetik und Ideologie, an dem historischen Wendepunkt Kriegsende zu beleuchten. Allen, die durch Rat und Kritik zu ihrem - wie auch immer vorläufigen - Abschluß beitrugen, möchte ich an dieser Stelle meinen herzlichen Dank aussprechen.

Herr Prof. Eberhard Lämmert begleitete meine Arbeit mit nie erlahmendem, anspornendem Interesse und richtete durch seine wertvollen Anregungen Wegmarken für ihren Fortgang auf.

Herr Dr. Walther Huder, Leiter des Literaturarchivs der Akademie der Künste, Berlin und Herr Dr. Paul Raabe, Leiter des Literaturarchivs des Schiller-Nationalmuseums in Marbach, gaben mir eine Fülle wichtiger Hinweise und Informationen.

Herrn Dr. Kurt Pinthus verdanke ich lebhafte und lebensnahe Einblicke in die Zeit des Expressionismus, die er in seinen Erzählungen und erinnernden Berichten eröffnete.

Die Gespräche mit Herrn Prof. R. Hinton Thomas waren für meine Studie von großem Gewinn.

Den Genannten und allen Freunden, die durch Vorschläge, Ermutigung und Kritik meine Arbeit förderten, gilt mein Dank.

Birmingham, im September 1969

Eva KolinskY 


\section{INHALT}

Einleitung $\ldots \ldots \ldots \ldots \ldots \ldots \ldots \ldots \ldots \ldots \ldots \ldots \ldots \ldots \ldots$

ERSter TeIL: Der erste WeltKRIEg UND DIR ENTWÜRfe EINER NeUEN Welt IN LITERARISCHEN ZEITSCHRIFTEN DES EXPRESSIONISMUS . . . . . . . . . .

1. Kriegsgegnerschaft und Kriegskritik in den literarischen Zeitschriften "Die Aktion", "Die Weissen Blätter«, "Der Sturm« ... . . . . . . . . . . 8

a. Organe der Kriegskritik . . . . . . . . . . . . . . . 8

b. Die Kritik des Krieges in der Zeitschrift $"$ Die Aktion* . . . . . . . . . . . 13

Die kriegskritische Funktion sakraler Thematik: das Sonderheft "Weihnachten 1917 « 14 - Die kriegskritische Funktion des Bildes vom Tod Gottes 17 - "Verse vom Schlachtfeld" im letzten Jahr des Krieges 22 - »Möglichkeiten, Wege, Forderungen «: Zeitkritik und Erneuerungspostulate in der "Aktion « 29

c. Die Kritik des Krieges in der Zeitschrift "Die Weissen Blätter" . . . . . . . . Die Kriegskritik der "Weissen Blätter« im letzten Jahr des Krieges 37 - Zum Verhältnis von Mensch, Maschine und Krieg in den "Weissen Blättern" 39 Kriegsende und Erneuerung in den "Weissen Blättern * 44

d. Die Stellung der Zeitschrift "Der Sturm» zum Krieg . . . . . . . . . . . . 45

2. Der Krieg als Wegbereiter einer neuen Welt . . . . . . . . . . . 49

a. Erneuerung als »äußerer« Gesamtvorgang . . . . . . . . . . . . 49

b. Erneuerung als "innerer" Vorgang: Die Wandlung des einzelnen Menschen . . 52

3. Der Mensch als Träger von Erneuerung. Zur Rolle des Subjektes in utopischen Entwürfen des Expressionismus . . . . . . . . . . . . 59

a. Der soziale Standort des Protagonisten . . . . . . . . . . . . 61

b. Die Vorherrschaft der Subjekte. Zum Verhältnis der Protagonisten zur Masse 64

c. Der Künstler als Protagonist innerer Erneuerung . . . . . . . . . . . . 68 Die Wesensaussage als Problem 68 - Die Führerrolle des Künstlers 72

Zweiter Teil: Der Eingriff DeR Dichter In die Politik NaCh Kriegsende und

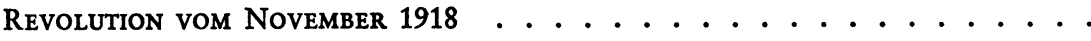

4. Weltwende und Sozialismus. Zum politisch-kritischen Ort literarischer Zeitschriften, deren Bezugsgruppe eine politische Partei bildet . . . . . . . . . . 84

a. Der politisch-kritische Ort der "Aktion" nach der deutschen Revolution . . .

Die organisatorische Bindung der »Aktion « $84-$ Das politische Selbstverständnis der A. S. P. 87 - Der Stand der revolutionären Hoffnungen im 9. Jahrgang der »Aktion« 90 
b. Der politisch-kritische Ort der Zeitschrift "Das Forum" nach November 1918 Revolution und geistige Internationale in der Zeitschrift "Das Forum" 92 Geistige Revolution und Sozialismus in der Zeitschrift "Das Forum«. Der Bezug zur Internationale des Gedankens »Clarté« 94

c. Der politisch-kritische Ort der Anthologie "Die Gemeinschaft" . . . . . .

5. Politik des neuen Menschen. Zum politisch-kritischen Ort literarischer Zeitschriften, deren Bezugsgruppe keine politische Partei bildet . . . . . . . . . .

a. Der politisch-kritische Ort der "Weissen Blätter» . . . . . . . . . . 98

Die Kritik der "Weissen Blätter« an der russischen Form des Sozialismus 99 Die Kritik der "Weissen Blätter" an der Entwicklung in Deutschland 102 Die Bindung der "Weissen Blätter" an die Internationale des Gedankens, »Clarté« 103

b. "Revolution. An Alle und Einen" und »Neue Erde». Der Entwurf einer Revolution des Menschen in Friedrich Burschells Zeitschriften . . . . . . .

6. Politik der Jüngsten. Zum literarisch-politischen Ort der zweiten Generation des Expressionismus

a. Die Dresdner Zeitschrift für neue Kunst, »Menschen" . . . . . . . . . . . Die Programmatik der Zeitschrift "Menschen«; ihr Ort zwischen Kunst und Politik 112 - Die Räte geistiger Arbeiter 116 - Die unpolitischen Züge sozialistischer Politik in der Zeitschrift "Menschen « 120

b. Ansätze einer Kritik des politischen Engagements des Expressionismus in der Zeitschrift "Das Tribunal . . . . . . . . . . . . . . . .

7. Politische Lyrik und Dichtung der Jüngsten. Neue ästhetische Akzente nach der Revolution 1918 in literarischen Zeitschriften des Expressionismus . . . . . .

a. Revolutionsgedichte. Menschheitserneuerung und Sozialismus in der "Aktionslyrik" von 1919 . . . . . . . . . . . . . . . . . . . . . . Die Revolution der Menschheit 132 - Revolution der Menschheit und Zeitkritik 134 - Revolution des Proletariats 135 - Das heilige Land der Revolution 138 - Die Erlösergestalten der Revolution 139

b. Ansätze und Wege neuer Kunst der zweiten expressionistischen Generation . . 146 Manifeste zur Revolution 149 - Die Ortsbestimmung des Künstlers als Gegenstand von Kunst, aufgewiesen an Gedichten Heinar Schillings 151 - Die Identität von Ich und Welt als Gegenstand von Kunst und Kunstkritik 157 - Kunst als Programm: Sturmkunst und Hamburger Expressionisten als Programmatiker der Kunst 161

8. Zusammenfassung ................... 164

9. Anmerkungen . . . . . . . . . . . . . . . . 168

10. Bibliographie . . . . . . . . . . . . . . . 217

Register . . . . . . . . . . . . . . . . 229 